Research paper

\title{
Systemic and compartmentalized immune response in canine visceral leishmaniasis
}

\author{
Alexandre Barbosa Reis ${ }^{\mathrm{a}, \mathrm{b}, *}$, Olindo Assis Martins-Filho ${ }^{\mathrm{c}}$, Andréa Teixeira-Carvalho ${ }^{\mathrm{a}, \mathrm{c}}$, \\ Rodolfo Cordeiro Giunchetti ${ }^{\mathrm{a}, \mathrm{b}}$, Cláudia Martins Carneiro ${ }^{\mathrm{a}}$, Wilson Mayrink ${ }^{\mathrm{d}}$, \\ Washington Luiz Tafuri ${ }^{a}$, Rodrigo Corrêa-Oliveira ${ }^{b}$ \\ a Laboratório de Imunopatologia, Núcleo de Pesquisa em Ciências Biológicas/NUPEB, Departamento de Análises Clínicas, Escola de Farmácia, Universidade Federal \\ de Ouro Preto, Ouro Preto, Minas Gerais, Brazil \\ ${ }^{\mathrm{b}}$ Laboratório de Imunologia Celular e Molecular, Centro de Pesquisas René Rachou, Fundação Oswaldo Cruz, Belo Horizonte, Minas Gerais, Brazil \\ ${ }^{\mathrm{c}}$ Laboratório de Biomarcadores de Diagnóstico e Monitoração, Centro de Pesquisas René Rachou, Fundação Oswaldo Cruz, Belo Horizonte, Minas Gerais, Brazil \\ d Laboratório de Leishmanioses, Departamento de Parasitologia, Instituto de Ciências Biológicas, Universidade Federal de Minas Gerais, Belo Horizonte, \\ Minas Gerais, Brazil
}

\section{A R T I C L E I N F O}

\section{Keywords:}

Canine visceral leishmaniasis

Clinical status

Parasite density

Immunophenotyping

\begin{abstract}
A B S T R A C T
Human visceral leishmaniasis $(\mathrm{VL})$ and canine visceral leishmaniasis $(\mathrm{CVL})$ are the most important emerging diseases with high prevalence in Latin American countries and are mainly caused by Leishmania $(L$. $)$ chagasi $($ Syn $=L$. infantum $)$. CVL has a great impact on Brazilian public health because domestic dogs are the most important VL peri-domicile reservoirs in both urban and peri-urban areas. Our findings highlight the complexity of cellular immunological events related to the natural infection from dogs by $L$. chagasi, additionally correlating major peripheral blood phenotypic markers with clinical status and tissues parasite density. Our main results demonstrated that lower frequency of circulating B cells and monocytes are important markers of severe CVL, whereas increased levels of $\mathrm{CD}^{+}$lymphocytes appear to be the major phenotypic feature of asymptomatic disease. Determination of the isotypes patterns during CVL demonstrated that asymptomatic dogs and those with low parasitism are associated with an increase of $\operatorname{IgG1}$, while the symptomatic dogs and those with high parasitism are associated with an increase of IgG, IgG2, IgM, IgA and IgE immunoglobulins. Pioneer findings obtained by our group showed a correlation between clinical status of CVL with degree of tissue parasite density. This data demonstrated that asymptomatic dogs presented low parasitism while symptomatic dogs are associated with high parasite load in various tissues such as skin, bone marrow and spleen. We have also investigated the association between tissue parasitism and CVL clinical forms. Regardless of clinical status, skin and spleen are the major sites of high parasite density during ongoing CVL. Furthermore, we demonstrated that bone marrow and spleen parasite density are the most reliable parasitological markers to decode the clinical status of CVL. In this article, we have reviewed some aspects
\end{abstract}

\footnotetext{
* Corresponding author at: Laboratório de Imunopatologia, Núcleo de Pesquisa em Ciências Biológicas, ICEB II, Morro do Cruzeiro, Universidade Federal de Ouro Preto, Ouro Preto, MG, CEP 35400-000, Brazil. Tel.: +55 21313559 1694; fax: +55 213135591680.

E-mail address: alexreis@nupeb.ufop.br (A.B. Reis).

Abbreviations: VL, visceral leishmaniasis; CVL, canine visceral leishmaniasis; WHO, world health organization; AD, asymptomatic dogs; OD, oligosymptomatic dogs; SD, symptomatic dogs; IFAT, indirect immunofluorescence assay; ELISA, enzyme linked immunosorbent assay; LDU, leishman donovan units; Ig, immunoglobulins; LP, low parasitism; MP, medium parasitism; HP, high parasitism; qPCR, quantitative real-time PCR; LST, leishmanin skin test; PBMC, peripheral blood mononuclear cells; IFN- $\gamma$, interferon-gamma; TNF- $\alpha$, tumor necrosis factor-alpha; LN, lymph node; Th, T helper; IL, interleukin; T-bet, Th1-specific T box transcription factor; IP-10, human interferon-inducible protein 10; RANTES, regulated upon activation, normal T-cell expressed and secreted; TGF- $\beta$, transformation growth factor-beta.
} 
of the histopathological and immunological events occurring in natural and experimental L. chagasi/L. infantum infection, pointing out the main $L$. chagasi-parasitized tissue. We have discussed the importance of the association between parasite density, immunological/histopathological aspects and clinical status of the CVL, their current applications, challenges for the future and potential opportunities in CVL research.

(c) 2008 Elsevier B.V. All rights reserved.

\section{Impact of canine control on the epidemiology from canine and human visceral leishmaniasis}

Visceral leishmaniasis (VL) is one of the most important emerging diseases with high prevalence in Latin American countries (Tesh, 1995). VL and canine visceral leishmaniasis (CVL) are mainly caused by Leishmania (L.) chagasi $($ Syn $=$ L. infantum $)$ in South America and Europe (Mauricio et al., 2000). Peri-domestic sand flies acquire the etiological agent by feeding on infected wild/domestic reservoirs and transmit it, causing severe disease in humans (Tesh, 1995; WHO, 2000). Nowadays, VL is currently expanding worldwide, mainly in Brazil, where recently, the typically rural outline has shifted to a progressively urbanized profile (Palatnik-de-Sousa et al., 2001). VL and CVL have a great impact on Brazilian public health because domestic dogs are the most important VL peri-domicile reservoirs in both urban and peri-urban areas (Reithinger and Davies, 1999; Palatnik-de-Sousa et al., 2001). The major prophylactic practice to control VL, as recommended by WHO, involves a systematic treatment of human cases, besides vector control by insecticide and Leishmania-seropositive dogs euthanasia (Tesh, 1995; Palatnik-de-Sousa et al., 2001). Control of CVL remains not completely established mainly because there is no effective vaccine available to be used for immunoprophylaxis (Gradoni, 2001; Giunchetti et al., 2007, 2008c,d). In the past 5 years, more than two million dogs were screened and more than 160,000 seropositive dogs were eliminated, but the incidence of human VL has not been reduced to an acceptable level (Braga et al., 1998). Moreover, drug treatment of infected dogs is expensive and unfortunately, different treatment strategies have failed to achieve a consistent parasitological cure for CVL owing to the permanence of latent Leishmania-infected cells (Baneth and Shaw, 2002; Noli and Auxilia, 2005). Based on either the similarity of clinical signs observed in human and dogs and the evolution of natural history of the disease, CVL has been suggested as a good model to better understand the pathogenesis of the human disease (Sanchez et al., 2004; Reis et al., 2006a).

\section{Clinical and biochemical/hematological biomarkers of progression in CVL}

Canine visceral leishmaniasis manifests itself as a broad clinical spectrum ranging from asymptomatic infection to patent severe disease, which mostly culminates in death (Reis et al., 2006b). According to Mancianti et al. (1988), asymptomatic dogs (AD) do not show visible clinical signs because they are apparently healthy animals (Fig. 1A), whereas oligosymptomatic dogs (OD) present some signs such as cutaneous ulcerations, frequently observed on the tip of the ears and on the periorbital areas, moderate weight loss and localized alopecia (Fig. 1B and C). Symptomatic dogs (SD) may show one or more typically clinical signs of CVL, such as cutaneous ulcerations all over the body, blindness, severe weight loss (anorexia), onychogryphosis, furfuraceous dermatitis, general alopecia, keratoconjuntivitis, progressing towards general morbidity state and death (Fig. 1D-J). From the localized cutaneous infection, the parasite can be disseminated via lymphatic or blood vessels, infecting macrophages of the bone marrow, lymph node (LN), liver and spleen, as well as kidney and gastrointestinal tract (Tryphomas et al., 1977; Keenan et al., 1984a). Initial clinical signs are hypertrophy of lymph node, dermatitis and periorbital and nasal dermatitis that could be disseminated. The opaque bristles, onychogryphosis and edema of the paws could be also found. Other signs such as fever, apathy, diarrhea, intestinal hemorrhage, weight loss, hepatosplenomegaly, hyperkeratosis, cutaneous ulceration, particularly on the nose, ears, tails and keratoconjunctivitis are frequent, although not necessarily present in all animals (Genaro et al., 1988; Dias et al., 1999).

The CVL presumptive diagnosis is generally performed by serological tests, such as indirect immunofluorescence assay test (IFAT) and enzyme linked immunosorbent assay (ELISA), associated with clinical and epidemiological records. The major problem regarding clinical diagnosis is the fact that CVL signs are very similar to those observed in other infectious diseases (Costa et al., 1991). The chronic aspect of the disease and its long incubation period may generate a delay or failure in clinical diagnosis (Cardoso and Cabral, 1998). Despite their high sensitivity, serological tests present a broad range of cross-reactions with other protozoan (Costa et al., 1991; Grimaldi and Tesh, 1993). However, the parasitological diagnosis presents generally low sensitivity when the tissue parasitism is scarce (Reis et al., 2006a). Considering the clinical forms of the disease, it was possible to define various biomarkers closely related to the parasitological, biochemical and hematological findings observed during clinical progression of the CVL. These findings include normocytic/ normochromic anemia and increase of total serum protein levels. It seems that biochemical alterations are linked to a polyclonal humoral immune response, which leads to a raised protein levels in serum (Marzochi et al., 1985; Reis et al., 2006a), characterized by hyperglobulinemia and hypoalbuminemia, besides of decreased albumin/globulin ratio (Cardoso and Cabral, 1998; Almeida et al., 2005; Strauss-Ayali et al., 2007). An impaired hematological status is associated with severe clinical aspects of CVL to be evidenced by marked anemia and leucopenia in decurrence of lymphopenia, eosinopenia and monocytopenia (Reis et al., 2006a,c). 


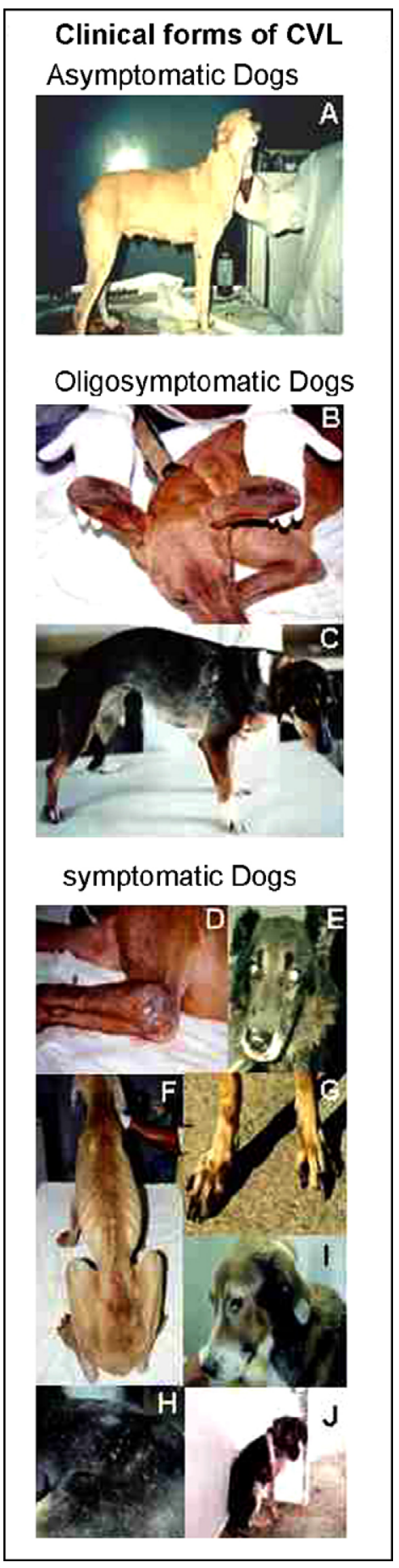

Fig. 1. Clinical status from dogs naturally infected by L. chagasi. (A) Asymptomatic dogs do not show visible clinical signs of the disease; (B and C) oligosymptomatic dogs present some signs of the disease such as cutaneous ulcerations on the tip of the ears and periorbital areas (B) as well as moderate weight loss and localized alopecia (C); (D-J) symptomatic dogs have disseminated cutaneous ulcerations (D), blindness $(E)$, severe weight loss $(F)$, onycogriphosis $(G)$, furfuraceous dermatitis (H), general alopecia, keratoconjuntivitis (I) and progress to forward general morbidity state $(\mathrm{J}) ; \mathrm{CVL}$, canine visceral leishmaniasis.

\section{Tissues parasite load and clinical progression in CVL}

Evaluation of parasite load by "leishman donovan units" (LDU), number of Leishmania amastigote by 1,000 nucleated cells (Stauber, 1955 modified by Reis et al., 2006a), and antiLeishmania detection by immunohistochemistry are important parasitological tools to verify parasite density in different lymphoid compartments (Tafuri et al., 2001, 2004; Sanchez et al., 2004; Reis et al., 2006a,b,c; Giunchetti et al., 2006, 2008a,b). In studies performed by our group, tissue parasitism for each compartment was initially classified as low (LP), medium (MP) or high (HP) parasitism based on tissue-specific LDU values statistically categorized into tertiles (Reis et al., 2006a,b). The data demonstrated that $\mathrm{AD}$ group presented low parasitism while SD group presented high parasite load in various tissues (skin, bone marrow, spleen, liver and lymph node) (Reis, 2001; Reis et al., 2006a,b,c; Giunchetti et al., 2006, 2008a,b). In this scope, our data showed correlations between AD group with low parasitism and SD group with high parasitism in skin, bone marrow and spleen (Reis et al., 2006b). Previous data obtained by our group has also investigated the association between tissue parasitism in distinct compartments and CVL clinical forms. Despite the clinical status, skin and spleen are the major sites of high parasite density during ongoing CVL (Reis et al., 2006b). Furthermore, we demonstrated that bone marrow and spleen parasite density are the most reliable parasitological markers to decode the clinical status of CVL (Reis et al., 2006b). More recently, Francino et al. (2006) proposed the quantitative real-time PCR (qPCR) to elucidate the status of dogs that are positive for Leishmania by conventional PCR, especially in endemic areas. The qPCR turned out to be also very useful to followup the parasite load in order to estimate the efficacy of the treatment, vaccines trials or the CVL evolution.

\section{Systemic immunological biomarkers of clinical progression in CVL}

In the last decade, various research groups have concentrated efforts studying immunopathology of dogs naturally and experimentally infected by $L$. chagasi/L. infantum (Cabral et al., 1992; Martinez-Moreno et al., 1993, 1995; Pinelli et al., 1994, 1995, 1999a,b; Brandonisio et al., 1996; Bourdoiseau et al., 1997; Nieto et al., 1999; Alvar et al., 2004; Tafuri et al., 2004; Solano-Gallego et al., 2004, 2005; Giunchetti et al., 2006; Reis et al., 2006a,b,c; StraussAyali et al., 2007; Lage et al., 2007; Cardoso et al., 2007; Rodriguez-Cortes et al., 2007; Giunchetti et al., 2008a,b). After the pioneering studies lead by Pinelli et al., some authors have searched immunological markers according to in vivo, ex vivo and in vitro context to evaluate clinical progression of CVL (Pinelli et al., 1994, 1995).

The in vivo analysis of the intradermal delayed hypersensitivity test, the leishmanin skin test (LST) (Montenegro, 1926), is an useful tool for both clinical diagnosis and epidemiological studies of human VL. The test is negative during the acute stage but it becomes and remains positive following the resolution of clinical symptoms (Reed et al., 1986; Badaró et al., 1986, 1996; Carvalho et al., 1992). The LST was also used for the 
diagnosis from a dog population in an endemic region of VL (Cardoso et al., 1998; Cabral et al., 1998). These authors showed that the prevalence of the infection increases considerably using LST to detect Leishmania-specific cellular immunity, in comparison with the prevalence obtained only by culture and serology, confirming that the prevalence and incidence of CVL have still been underestimated (Dye et al., 1993; Tesh, 1995). The use of the LST to evaluate in vivo immune status to distinguish asymptomatic and symptomatic dogs is also controversial, because the SD group might react in a similar manner to the AD group (Reis, 2001). Baleeiro et al. (2006) tested various antigens obtained by L. chagasi, Leishmania braziliensis and Leishmania amazonensis in VL endemic area in Brazil. These authors showed that the use of antigens from different Leishmania species might interfere with the results of the immunological tests performed in dogs naturally infected by $L$. chagasi. Further investigations will be necessary in an endemic area to define the role of the LST in natural and experimental Leishmania infections and its applications in vaccine trials to CVL.

In symptomatic CVL, cellular immune response is impaired, as indicated by studies showing that peripheral blood mononuclear cells (PBMC) from dogs fail to respond to parasite antigens both in vitro and in vivo. Protective immunity has generally been associated with a distinct cellular immune response, manifested by a strong proliferative response of PBMC to leishmanial antigens (Cabral et al., 1992; Carvalho et al., 1981; Sacks et al., 1987; Pinelli et al., 1999a,b) accompanied by the IFN- $\gamma$ and TNF$\alpha$ production, which are required for macrophage activation and killing of intracellular parasites (Kemp et al., 1993; Liew and O’Donell, 1993; Nacy et al., 1991; Pinelli et al., 1995).

The role of anti-leishmanial cellular and humoral immunity during systemic and compartmentalized immune response underlying the susceptibility/resistance during CVL has been recognized throughout ex vivo and in vitro investigations (Pinelli et al., 1994, 1995; Bourdoiseau et al., 1997; Solano-Gallego et al., 2001b, 2005; Reis et al., 2006a,b,c; Giunchetti et al., 2006, 2008a,b; Lage et al., 2007). In order to assess the cellular immune response, we used the immunophenotypic approaches by flow cytometry to study immunological features of circulating leucocytes as immunological markers for clinical status and bone marrow parasite density in dogs naturally infected by L. chagasi (Fig. 2) (Reis et al., 2006c). T cells analysis in the peripheral blood showed high levels of $\mathrm{CD}^{+}$ $T$ cells in AD and OD groups as compared to SD group. On the other hand, the SD group presented low levels of $C D 4^{+} \mathrm{T}$ cells as compared to $\mathrm{AD}$ group. $\mathrm{AD}$ and $\mathrm{OD}$ groups presented an increase of $\mathrm{CD}^{+} \mathrm{T}$ cells as compared to SD

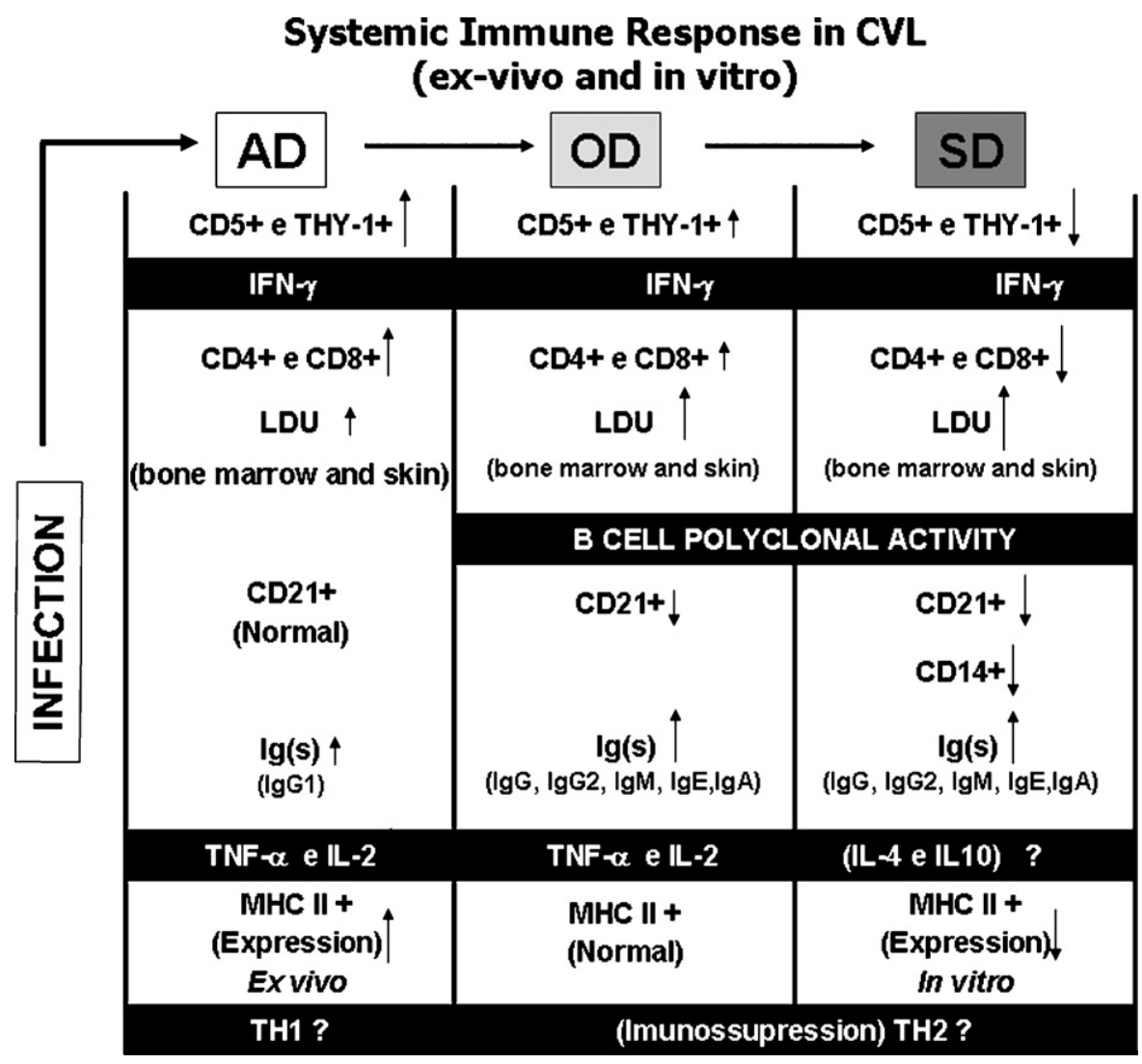

Fig. 2. Clinical status versus cellular and humoral immune response profile in the peripheral blood, bone marrow and skin from dogs naturally infected by $L$. chagasi; CVL, canine visceral leishmaniasis; AD, asymptomatic dogs; OD, oligosymptomatic dogs; SD, symptomatic dogs; LDU, leishman donovan units; Ig, immunoglobulins. 
and control groups. Interestingly, increased levels of CD8 ${ }^{+}$ lymphocytes appear to be the major phenotypic feature of asymptomatic disease. A decrease in the number of $B$ cells in SD group as compared to AD and control groups were also observed (Reis et al., 2006c). Moreover, a decrease in the number of circulating CD $14^{+}$monocytes in SD group as compared to control group was detected (Fig. 2). Furthermore, bone marrow parasite density is related closely to major phenotypic changes reported for peripheral blood leucocytes and pointed out as hallmarks of the clinical status of CVL. We observed a lower number of $\mathrm{CD}^{+} \mathrm{T}$ cells, their subpopulations $\left(\mathrm{CD} 4^{+}\right.$and $\left.\mathrm{CD}^{+}\right)$as well as a lower number of $B$ cells and monocytes mainly in dogs with high parasitism (Reis et al., 2006c). Several reports have focused on the relationship between distinct clinical forms of CVL, disease progression and the IgG isotype levels, in both experimental and natural $L$. (L.) infantum/L. (L.) chagasi infections (Solano-Gallego et al., 2000, 2001a,b; Leandro et al., 2001; Vercammen et al., 2002; Quinnell et al., 2003; Cordeiro-da-Silva et al., 2003). Although the majority of these investigations have been performed based on wellestablished ELISA and Western-blot protocols, controversial data on immunoglobulin isotype profiles are frequently documented. Increased levels of IgG and IgG2 have been indiscriminately reported for $\mathrm{AD}$ and SD groups as described by Bourdoiseau et al. (1997) and Vercammen et al. (2002). However, according to Deplazes et al. (1995), Nieto et al. (1999) and Solano-Gallego et al. (2001a,b), SD group showed considerably higher anti-Leishmania IgG1 antibodies in comparison to asymptomatic carriers. Additionally, Courtenay et al. (2002) and Quinnell et al. (2003) reported that higher levels of anti-Leishmania IgG/ IgG1 and lower levels of IgG2 were also observed in SD group (Day, 2007). However, Leandro et al. (2001) and Cordeiro-da-Silva et al. (2003) have documented increased levels of IgG2 in sera samples from infected animals, particularly in the case of SD group. Despite these controversial findings regarding the immunoglobulin isotype profile associated with CVL, it is clear that during canine Leishmania infection a dichotomous humoral immune response is triggered, similarly with the human infection (Anam et al., 1999). Recently, our group has studied the isotype patterns of immunoglobulins as hallmarks for clinical status and tissue parasite density from Brazilian dogs naturally infected by L. chagasi (Reis et al., 2006b). We have observed that AD and LP groups are associated with an increase of IgG1, while the SD and HP groups are associated with an increase of $\operatorname{IgG}$, IgG2, IgM, IgA and IgE immunoglobulins (Fig. 2).

\section{Compartmentalized immune response in different lymphoid organs in CVL}

Analysis of the immune response in different compartments during chronic infection is a useful new scientific strategy for the study of the immune response in parasitic/ infectious diseases. This approach allows simultaneous investigation of the immunological events observed in the peripheral blood and may indicate whether they are representative of those occurring in the lymphoid tissues (Teixeira-Carvalho et al., 2002).
Although CVL is known to be a severe systemic disease, there are a few studies describing detailed histopathological features of distinct host compartments affected by the parasite. Aiming to better understand events related to compartmentalized immunopathology of CVL, several research groups have performed a broad investigation focusing on histopathological, parasitological and immunological aspects of skin, spleen, liver and lymph nodes (LN) in dogs naturally and experimentally infected by $L$. chagasi.

The skin is the first point of contact with Leishmania from sand fly vectors, and recent investigations demonstrated that in endemic regions a large population of parasitized asymptomatic dogs is living (Berrahal et al., 1996; Cabral et al., 1998; Solano-Gallego et al., 2000, 2001a,b). Earlier reports of CVL described various macroscopical aspects of skin lesions (desquamation, alopecia, pustular dermatitis, ulcerative dermatosis and nodular disease), which may be associated with immune response (Adler and Theodor, 1932; Cunha, 1938; Torres, 1941; Ferrer et al., 1988). The histopathologic evaluation of the skin biopsies revealed that in all Leishmania-infected dogs the predominant inflammatory cells were macrophages. Lymphocytes and plasma cells were the second most frequent cell types.

Dos-Santos et al. (2004) showed that inflammatory infiltrates are a common histological finding in the skin of dogs regardless of the presence of parasites or evidence of infection with Leishmania. However, skin parasitism in CVL was always associated with inflammation. Macrophages infiltrates were more frequently associated with the presence of Leishmania and a higher parasite burden than pleomorphic focal or diffuse inflammatory infiltrate was found.

We have described that SD group presented intense dermal inflammatory infiltrate characterized as diffuse with a high parasitic burden, decrease in the levels of collagen type I and increase in collagen type III (Giunchetti et al., 2006) (Fig. 3A and B). Furthermore, sections stained with hematoxylin and eosin demonstrated a higher intensity of inflammatory changes in SD group than $\mathrm{AD}$ group. Correlation between cellular phenotypes and histological changes seemed to reflect cellular activation and leucocytes migration from peripheral blood to the skin, mediated by antigenic stimulation. The results suggested that chronic dermal inflammation and cutaneous parasitism were directly related to the severity of clinical disease (Giunchetti et al., 2006) as related by Martinez-Moreno et al. (1995), Tarantino et al. (2001) and Solano-Gallego et al. (2004).

Brachelente et al. (2005) demonstrated that the local immune response in CVL includes Th1 as well as Th2 cytokine subsets suggesting that increased expression of the Th2 cytokine-IL-4 is associated with both severe clinical signs and a high parasite burden in the skin lesions. In addition, Guarga et al. (2000) demonstrated that dogs naturally infected by $L$. infantum presenting lower count of $\mathrm{CD}^{+}$cells were more capability to infect sand fly vector.

Considering the spleen as one of the major affected organs during CVL, significant alterations in its morphology and immunological aspects become a relevant 

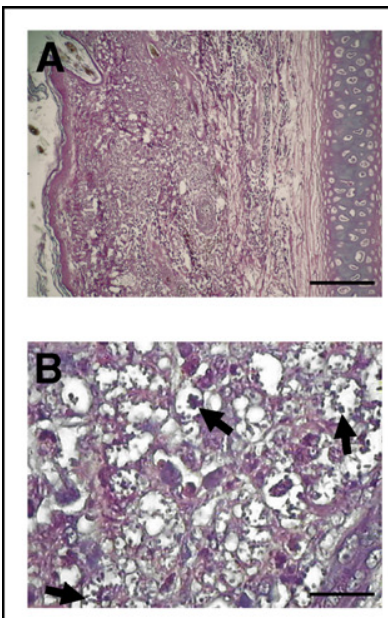

$\uparrow$ intensity of dermis inflammatory changes in $\mathrm{SD}$

\section{$\downarrow$ collagen type I and}

$\uparrow$ collagen type III in SD

$\uparrow$ parasite burden in SD by anti-Leishmania

immunohistochemistry and by LDU index
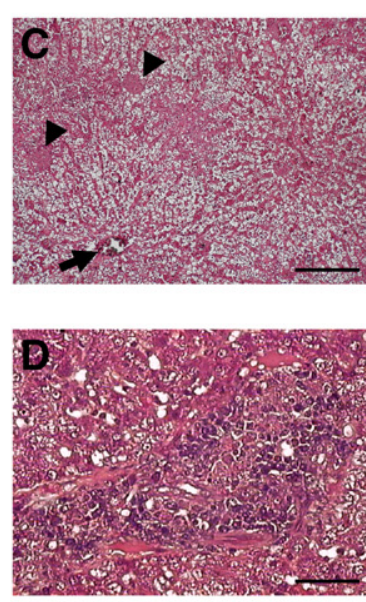

$\uparrow$ reaction of the Küpffer cells, capsule and portal inflammation, and the presence of intralobular granulomas in the different clinical groups

\section{$\uparrow$ parasite burden in SD by} anti-Leishmania

immunohistochemistry and by LDU index
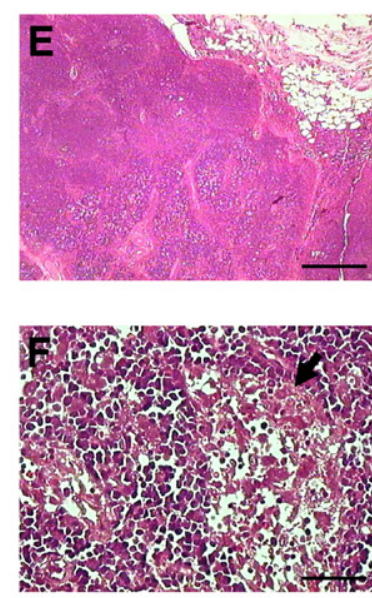

$\uparrow$ hypertrophy/hyperplasia of LN cortical and medullary zones in $A D$, whereas atrophy of $L N$ cortical zone in SD

$\uparrow$ T-lymphocytes, $\downarrow$ CD21+ Bcells and $\uparrow \mathrm{MHCll}$ expression by lymphocytes in LN Leishmania chagasi-infected dogs
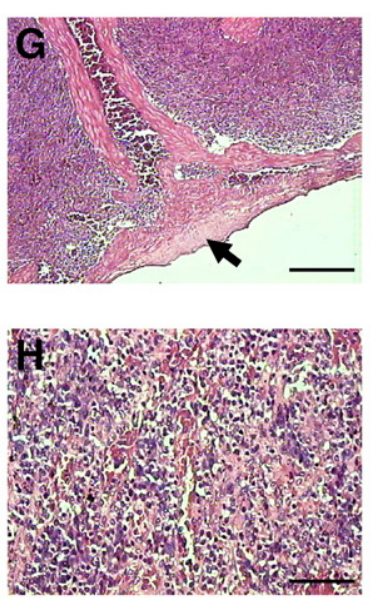

Intense reaction of the capsule inflammation, hypertrophy/hiperplasia in red pulp observed in the different clinical groups

$\uparrow$ parasite burden in SD by anti-Leishmania

immunohistochemistry and by LDU index

Fig. 3. Photomicroscopes of hematoxylin-eosin stained specimens highlighting the major histopathological features of Leishmania chagasi-infected dogs considering ear skin ( $A$ and $B$ ), liver ( $C$ and $D$ ), popliteal lymph node (E and F) and spleen ( $G$ and $H)$. (A) Chronic inflammation of the dermis showing sparse cellular infiltrates in the superficial and deep dermis $(\mathrm{bar}=200 \mu \mathrm{m}) ;(B)$ high parasite burden presenting amastigotes forms (arrowed) inside vacuolated macrophages in the ear skin $(\mathrm{bar}=50 \mu \mathrm{m})$; (C) granulomatous inflammatory reaction with intralobular granulomas dispersed in the hepatic parenchyma (arrow heads) and centrilobular vein (arrow) (bar $=200 \mu \mathrm{m}$ ); (D) inflammation of portal tract showing cellular mononuclear infiltrate characterized by plasmocytes, macrophages and lymphocytes (bar $=50 \mu \mathrm{m})$; (E) hypertrophy/hyperplasia of cortical and medullary regions observed in lymph node (bar $=500 \mu \mathrm{m}$ ); (F) chronic inflammation in the lymph node capsule with amastigotes forms (arrowed) inside vacuolated macrophages $(\mathrm{bar}=50 \mu \mathrm{m}) ;(\mathrm{G})$ inflammation of the splenic capsule showing capsule thickened (arrowed) suggesting collagen deposition (bar $=500 \mu \mathrm{m})$; $(\mathrm{H})$ hypertrophy/hyperplasia of red pulp showing cellular mononuclear infiltrate characterized by plasmocytes, macrophages and lymphocytes in spleen (bar $=50 \mu \mathrm{m})$. AD: asymptomatic dogs; SD: symptomatic dogs; LN: lymph node.

investigation, because it is a site where cell activation might occur during the infection. Since the contribution of the immune response in the genesis of splenomegaly during CVL is still unclear, we have developed a morphological and phenotypic analysis of spleen biopsies from dogs with CVL. In Fig. $3 \mathrm{G}$ and $\mathrm{H}$, the splenic tissue presents capsule inflammation more frequently in infected dogs as compared to control group. These alterations are more intense in $\mathrm{OD}$ and SD groups as compared to $\mathrm{AD}$ group. We also observed hypertrophy and hyperplasia in red pulp from spleen in all infected groups, characterized by mononuclear infiltrate cells, mainly plasmocytes. The white pulp presented the substitution of macrophage by lymphocytes in decurrence of hypertrophy and hyperplasia of this region (Fig. 3G and $\mathrm{H}$ ).

Recently, studies referring to the evaluation of cytokines profile in spleen cells from dogs naturally/experimentally infected by L. chagasi/L. infantum were conduced (Lage et al., 2007; Strauss-Ayali et al., 2007). Lage et al. evaluated the cytokines expression in splenocytes from dogs naturally infected by L. chagasi and did not detected differences on the TNF- $\alpha$, IL-12, IL-4, IFN- $\gamma$ and IL-10 levels when the dogs were classified by different clinical forms. However, when the dogs were categorized by different parasite load, the authors observed that hundred percent of dogs with high parasitism expressed IL-10 as compared to those with low and medium parasitism. These data suggest that CVL is marked by a balanced production of Th1/Th2 cytokines, with a predominant accumulation of IL-10, probably as a consequence of an increase in parasite load and progression of the disease. These data still showed a possible relationship between intensity of splenic parasitism and evolution of the clinical manifestations of CVL (Lage et al., 2007).

Strauss-Ayali et al. developed a study investigating the immune response in splenocytes of $L$. infantum-infected dogs following experimental and natural infection. Increased levels on IFN- $\gamma$, T-bet, IP-10 and RANTES were observed in all evaluated groups. IL-4 levels increased as early as one month after experimental infection, while IL-5 was high at later stages. IL-10 and TGF- $\beta$ did not change during the infection. The study indicated that both type-1 and type-2 immune responses occur in the spleen during CVL and suggested that the early elevation of IL- 4 might 
have a role in the persistence of parasites in the presence of high IFN- $\gamma$ expression.

The immunopathological evaluation of the hepatic compartment associated with parasitism and biochemical findings have been also performed in order to better understand the genesis of hepatomegaly in CVL (Giunchetti et al., 2008b). Intense reaction of the Kupffer cells, capsule and portal inflammation and the presence of intralobular granulomas were observed in the different clinical groups (Fig. 3C and D). SD group presented a higher frequency of parasitism as compared to AD group. Inflammatory alterations were more intense in the SD group and were associated with parasitism. Moreover, the results indicated an association between histological liver changes (inflammation of the hepatic capsule, portal inflammation, and hypertrophy/hyperplasia of the Kupffer cells) and the enhancement of biochemical alterations (plasmatic globulin) according to progression of clinical forms of CVL.

Despite LN is one of the most relevant lymphoid tissues involved in the parasite-host interface during $L$. chagasi infection, the cellular and molecular basis of the compartmentalized immune response as well as histopathology into LN is not completely established. There are only few studies focusing on the LN during CVL (Keenan et al., 1984a,b; Martinez-Moreno et al., 1993; Tafuri et al., 2001; Lima et al., 2004; Giunchetti et al., 2008a). A detailed histopathologic analysis was performed by our group aim to increment information about parasite load and major immunophenotypic features of the LN in $L$. chagasiinfected dogs (Giunchetti et al., 2008a). Our major histopathological findings highlighted that hypertrophy/ hyperplasia of LN cortical and medullary zones were the principal characteristics observed in AD group, whereas atrophy of LN cortical zone was predominant feature in SD group (Fig. 3E and F).

In CVL, lymphadenopathy is usually defined as an increase in LN size (enlargement of LN), usually described as a regional or generalized alteration (Rogers et al., 1993). It has been demonstrated that all LN from L. chagasiinfected dogs display a chronic lymphadenitis, regardless of the anatomical region analyzed, with hypertrophy/ hyperplasia of cortical and medullary zones (Lima et al., 2004). However, the clinical status or the tissue parasitism load might not be directly related to the intensity of the lesions, once previous data demonstrated that AD group presented higher LN parasitism than OD or SD groups (Giunchetti et al., 2008a).

\section{Conclusion and new challenges}

Our findings highlight the complexity of cellular immunological events related to natural infection from dogs by L. chagasi, correlating major peripheral blood phenotypic markers with clinical status and tissues parasite density. Our data suggest that the sustained $\mathrm{T}$ cell compartment (both $\mathrm{CD}^{+}$and $\mathrm{CD}^{+} \mathrm{T}$ cells) observed in $\mathrm{AD}$ and $\mathrm{LP}$ groups may be resultant from the high activity of the host immune system to perform antigen presentation and to remove parasites from affected sites. Lower frequency of circulating $B$ cells and monocytes are important markers of severe CVL, whereas increased levels of $\mathrm{CD}^{+}$lymphocytes appear to be the major phenotypic feature of asymptomatic disease. Despite the clinical status, skin and spleen are the major sites of high parasite density during ongoing CVL. Furthermore, we demonstrated that bone marrow and spleen parasite density are the most reliable parasitological markers to decode the clinical status of CVL.

Additional studies on the specificities of the activated cells and their both cytokine and chemokine profiles may provide important information that will lead to a better understanding of the immunological/inflammatory events that take place in the distinct lymphoid compartments during canine visceral leishmaniasis.

\section{Conflict of interest}

None.

\section{Acknowledgements}

The authors wish to express their appreciation for the hard work carried out by the kennel staff of the Universidade Federal de Ouro Preto and Universidade Federal de Minas Gerais for their special dedication during the execution of this project. We also thank the people from Fundação Nacional da Saúde, Ministério da Saúde, Distrito Regional de Belo Horizonte, Minas Gerais, for their special dedication to this work. The authors are also grateful for the use of the facilities at CEBIO, Universidade Federal de Minas Gerais and Rede Mineira de Bioterismo (FAPEMIG). This work was supported by Fundação de Amparo à Pesquisa do Estado de Minas Gerais, Brazil (FAPEMIG grant: CBS 2222/97, CBB CBB9202 and PRONEX 2007), PAPES IIIb and PAPES IVb (FIOCRUZ/RJ/2002-2005; 2006-2008), Conselho Nacional de Pesquisa (CNPq grant: 521124/98-0) and Coordenação de Aperfeiçoamento de Pessoal de Nível Superior (CAPES). ABR, OAMF, WLT, WM and RCO are grateful by the CNPq fellowships.

\section{References}

Adler, S., Theodor, O., 1932. Investigations on Mediterranean kala-azar. VI-Canine visceral leishmaniasis. Proc. R. Soc. Lond. 110, 402-412.

Almeida, M.A., Jesus, E.E., Sousa-Atta, M.L., Alves, L.C., Berne, M.E., Atta, A.M., 2005. Clinical and serological aspects of visceral leishmaniasis in northeast Brazilian dogs naturally infected with Leishmania chagasi. Vet. Parasitol. 127, 227-232.

Alvar, J., Cañavate, C., Molina, R., Moreno, J., Nieto, J., 2004. Canine leishmaniasis. Adv. Parasitol. 57, 1-88.

Anam, K., Afrin, F., Banerjee, D., Pramanik, N., Guha, S.K., Goswami, R.P. Gupta, P.N., Saha, S.K., Ali, N., 1999. Immunoglobulin subclass distribution and diagnostic value of Leishmania donovani antigen-specific immunoglobulin G3 in Indian kala-azar patients. Clin. Diagn. Lab. Immunol. 6, 231-235.

Baneth, G., Shaw, S.E., 2002. Chemotherapy of canine leishmanioses. Vet. Parasitol. 106, 315-324.

Baleeiro, C.O., Paranhos-Silva, M., dos Santos, J.C., Oliveira, G.G., Nascimento, E.G., de Carvalho, L.P., dos-Santos, W.L., 2006. Montenegro's skin reactions and antibodies against different Leishmania species in dogs from a visceral leishmaniosis endemic area. Vet. Parasitol. 139, 21-28.

Badaró, R., Jones, T.C., Carvalho, E.M., Sampaio, D., Reed, S.G., Barral, A., Teixeira, R., Johnson Jr., W.D., 1986. New perspectives on a subclinical form of visceral leishmaniasis. J. Infect. Dis. 154, 1003-1011.

Badaró, R., Benson, D., Eulalio, M.C., Freire, M., Cunha, S., Netto, E.M., Pedral-Sampaio, D., Madureira, C., Burns, J.M., Houghton, R.L., David, 
J.R., Reed, S.G., 1996. rK39: a cloned antigen of Leishmania chagasi that predicts active visceral leishmaniasis. J. Infect. Dis. 173, 758-761.

Berrahal, F., Mary, C., Roze, M., Berenger, A., Escoffier, K., Lamouroux, D., Dunan, S., 1996. Canine leishmaniasis: identification of asymptomatic carriers by polymerase chain reaction and immunoblotting. Am. J. Trop. Med. Hyg. 55, 273-277.

Bourdoiseau, G., Bonnefont, C., Magnol, J.P., Saint-Anré, I., Chabanne, L., 1997. Lymphocyte subset abnormalities in canine leishmaniasis. Vet. Immunol. Immunopathol. 56, 345-351.

Brachelente, C., Muller, N., Doherr, M.G., Sattler, U., Welle, M., 2005. Cutaneous leishmaniasis in naturally infected dogs is associated with a T helper-2-biased immune response. Vet. Pathol. 42, 166175.

Braga, M.D., Coelho, I.C., Pompeu, M.M., Evans, T.G., MacAullife, I.T., Teixeira, M.J., Lima, J.W., 1998. Control of canine visceral leishmaniasis: comparison of results from a rapid elimination program of serum-reactive dogs using an immunoenzyme assay and slower elimination of serum-reactive dogs using filter paper elution indirect immunofluorescence. Rev. Soc. Bras. Med. Trop. 31, 419-424.

Brandonisio, O., Panunzio, M., Faliero, S.M., Ceci, L., Fasanella, A., Puccini, V., 1996. Evaluation of polymorphonuclear cell and monocyte functions in Leishmania infantum-infected dogs. Vet. Immunol. Immunopathol. 53, 95-103.

Cabral, M., O'Grady, J., Alexander, J., 1992. Demonstration of Leishmania specific cell mediated and humoral immunity in asymptomatic dogs. Parasite Immunol. 14, 531-539.

Cabral, M., O'grady, J.E., Gomes, S., Sousa, J.C., Thompson, H., Alexander, J., 1998. The immunology of canine leishmaniasis: strong evidence for a developing disease spectrum from asymptomatic dogs. Vet. Immunol. Immunopathol. 76, 173-180.

Cardoso, L., Neto, F., Sousa, J.C., Rodrigues, M., Cabral, M., 1998. Use of a leishmanin skin test in the detection of canine Leishmania-specific cellular immunity. Vet. Parasitol. 79, 213-220.

Cardoso, L., Cabral, M., 1998. Leishmania and canine Leishmaniasis. Rev. Port. C. Vet. XCIII (527), 122-141.

Cardoso, L., Schallig, H.D., Cordeiro-da-Silva, A., Cabral, M., Alunda, J.M., Rodrigues, M., 2007. Anti-Leishmania humoral and cellular immune responses in naturally infected symptomatic and asymptomatic dogs. Vet. Immunol. Immunopathol. 117, 35-41.

Carvalho, E.M., Teixeira, R.S., Johnson Jr., W.D., 1981. Cell-mediated immunity in American visceral leishmaniasis. Infect. Immun. 48, 409-414.

Carvalho, E.M., Barral, A., Pedral-Sampaio, D., Barral-Netto, M., Badaró, R. Rocha, H., Johnson Jr., W.D., 1992. Immunologic markers of clinical evolution in children recently infected with Leishmania donovani chagasi. J. Infect. Dis. 165, 535-540.

Cordeiro-da-Silva, A., Cardoso, L., Araujo, N., Castro, H., Tomas, A., Rodrigues, M., Cabral, M., Vergnes, B., Sereno, D., Ouaissi, A., 2003. Identification of antibodies to Leishmania silent information regulatory 2 (SIR2) protein homologue during canine natural infections: pathological implications. Immunol. Lett. 86, 155-162.

Courtenay, O., Quinnell, R.J., Garcez, L.M., Shaw, J.J., Dye, C., 2002. Infectiousness in a cohort of Brazilian dogs: why culling fails to contro visceral leishmaniasis in areas of high transmission. J. Infect. Dis. 186, 1314-1320.

Costa, C.A., Genaro, O., Lana, M., Magalhães, P.A., Dias, M., Michalick, M.S., Melo, M.N., Costa, R.T., Magalhães-Rocha, M.N., Mayrink, W., 1991. Leishmaniose visceral canina: avaliação da metodologia sorológica utilizada em inquéritos epidemiológicos. Rev. Soc. Med. Trop. 24, $21-$ 25.

Cunha, A.M., 1938. Infecções experimentais na leishmaniose visceral americana. Mem. Inst. Oswaldo Cruz 33, 581-598.

Day, M.J., 2007. Immunoglobulin G subclass distribution in canine leishmaniosis: a review and analysis of pitfalls in interpretation. Vet. Parasitol. 147, 2-8.

Deplazes, P., Smith, N.C., Arnold, P., Lutz, H., Eckert, J., 1995. Specific IgG1 and IgG2 antibody responses of dogs to Leishmania infantum and other parasites. Parasite Immunol. 17, 451-458.

Dias, D.V., Da Costa, C.A., Toledo, V.P.C.P., Bambirra, E., Genaro, O., Michalick, M.S.M., Costa, R.T., Mayrink, W., Oréfice, F., 1999. Leishmaniose visceral canina - Estudo parasitológico e histológico em olhos de cães - Parte I. Rev. Bras. Oftal. 58, 331-337.

Dos-Santos, W.L., David, J., Badaró, R., de-Freitas, L.A., 2004. Association between skin parasitism and a granulomatous inflammatory pattern in canine visceral leishmaniosis. Parasitol. Res. 92, 89-94.

Dye, C., Vidor, E., Dereure, J., 1993. Serological diagnosis of leishmaniasis: on detecting infection as well as disease. Epidemiol. Infect. 110, 647656.

Ferrer, L., Rabanal, R., Fondevila, D., Ramos, J.A., Domingo, M., 1988. Skin lesions in canine leishmaniasis. J. Small. Anim. Pract. 29, 381-388.
Francino, O., Altet, L., Sanchez-Robert, E., Rodriguez, A., Solano-Gallego, L., Alberola, J., Ferrer, L., Sanchez, A., Roura, X., 2006. Advantages of realtime PCR assay for diagnosis and monitoring of canine leishmaniosis. Vet. Parasitol. 137, 214-221.

Genaro, O., Mayrink, W., Michalick, M.S.M., Dias, M., Da Costa, C.A., Melo, M.N., 1988. Naturally occurring visceral leishmaniasis in dogs: clinical aspects. Mem. Inst. Oswaldo Cruz 83, 43.

Giunchetti, R.C., Mayrink, W., Genaro, O., Carneiro, C.M., Corrêa-Oliveira, R., Martins-Filho, O.A., Marques, M.J., Tafuri, W.L., Reis, A.B., 2006. Relationship between canine visceral leishmaniosis and the Leishmania (Leishmania) chagasi burden in dermal inflammatory foci. J. Comp. Pathol. 135, 100-107.

Giunchetti, R.C., Martins-Filho, O.A., Carneiro, C.M., Mayrink, W., Marques, M.J., Tafuri, W.L., Correa-Oliveira, R., Reis, A.B., 2008a. Histopathology, parasite density and cell phenotypes of the popliteal lymph node in canine visceral leishmaniasis. Vet. Immunol. Immunopathol. 121, $23-$ 33.

Giunchetti, R.C., Mayrink, W., Carneiro, C.M., Correa-Oliveira, R., MartinsFilho, O.A., Marques, M.J., Tafuri, W.L., Reis, A.B., 2008b. Histopathological and immunohistochemical investigations of the hepatic compartment associated with parasitism and serum biochemical changes in canine visceral leishmaniasis. Res. Vet. Sci. 84, 269-277.

Giunchetti, R.C., Corrêa-Oliveira, R., Martins-Filho, O.A., Teixeira-Carvalho, A., Roatt, B.M., Aguiar-Soares, R.D.O., Vitoriano-Souza, J., Moreira, N.D., Malaquias, L.C.C., Castro, L.L.M., Lana, M., Reis, A.B., 2007. Immunogenicity of a killed Leishmania vaccine with saponin adjuvant in dogs. Vaccine 25, 7674-7686.

Giunchetti, R.C., Reis, A.B., da Silveira-Lemos, D., Martins-Filho, O.A., Correa-Oliveira, R., Bethony, J., Vale, A.M., da Silva Quetz, J., Bueno, L.L., Franca-Silva, J.C., Nascimento, E., Mayrink, W., Fujiwara, R.T., 2008c. Antigenicity of a whole parasite vaccine as promising candidate against canine leishmaniasis. Res. Vet. Sci. 85, 106-112.

Giunchetti, R.C., Correa-Oliveira, R., Martins-Filho, O.A., Teixeira-Carvalho, A., Roatt, B.M., Aguiar-Soares, R.D.O., Coura-Vital, W., de Abreu, R.T., Malaquias, L.C., Gontijo, N.F., Brodskyn, C., de Oliveira, C.I., Costa, D.J., Lana, M., Reis, A.B., 2008d. A killed Leishmania vaccine with sand fly saliva extract and saponin adjuvant displays immunogenicity in dogs. Vaccine 26, 623-638.

Gradoni, L., 2001. An update on antileishmanial vaccine candidates and prospects for a canine Leishmania vaccine. Vet. Parasitol. 100, 87103.

Grimaldi Jr., G., Tesh, R.B., 1993. Leismanioses of the new world: current concepts and implications for future research. Clin. Microbiol. Ver. 6, 230-250.

Guarga, J.L., Moreno, J., Lucientes, J., Gracia, M.J., Peribanez, M.A., Alvar, J., Castillo, J.A., 2000. Canine leishmaniasis transmission: higher infectivity amongst naturally infected dogs to sand flies is associated with lower proportions of T helper cells. Res. Vet. Sci. 69, 249-253.

Kemp, M., Kurtzhals, J.A., Bendtzen, K., Poulsen, L.K., Hansen, M.B., Koech, D.K., Kharazmi, A., Theander, T.G., 1993. Leishmania donovani-reactive Th1- and Th2-like T-cell clones from individuals who have recovered from visceral leishmaniasis. Infect. Immun. 61, 1069-1073.

Keenan, C.M., Hendricks, L.D., Lightner, L., Webster, H.K., Johnson, A.J., 1984a. Visceral leishmaniasis in the German shepherd dog. I. Infection, clinical disease, and clinical pathology. Vet. Pathol. 21, 74-79.

Keenan, C.M., Hendricks, L.D., Lightner, L., Johnson, A.J., 1984b. Visceral leishmaniasis in the German shepherd dog. II. Pathology. Vet. Pathol. $21,80-86$.

Lage, R.S., Oliveira, G.C., Buzek, S.C.U., Guerra, L.L., Giunchetti, R.C., CorrêaOliveira, R., Reis, A.B., 2007. Analysis of the cytokine profile in spleen cells from dogs naturally infected by Leishmania chagasi. Vet. Immunol. Immunopathol. 115, 135-145.

Leandro, C., Santos-Gomes, G.M., Campino, L., Romão, P., Cortes, S., Rolao, N., Gomes-Pereira, S., Rica Capela, M.J., Abranches, P., 2001. Cell mediated immunity and specific $\operatorname{IgG} 1$ and $\operatorname{IgG} 2$ antibody response in natural and experimental canine leishmaniosis. Vet. Immunol. Immunopathol. 79, 273-284.

Liew, F.Y., O'Donell, C.A., 1993. Immunology of leishmaniasis. Adv. Parasitol. 32, 161-259.

Lima, W.G., Michalick, M.S.M., Melo, M.N., Tafuri, W.L., Tafuri, Wg.L., 2004. Canine visceral leishmaniasis: a histopathological study of lymph nodes. Acta Trop. 92, 43-53.

Mancianti, F., Gramiccia, M., Gradoni, L., Pieri, S., 1988. Studies on canine leishmaniais control. I. Evolution of infection of different clinical forms of canine leishmaniasis following antimonial treatment. $R$. Soc. Trop. Med. Hyg. 82, 566-567.

Martinez-Moreno, A., Martinez-Cruz, M.S., Blanco, A., Hernandez-Rodriguez, S., 1993. Immunological and histological study of T- and Blymphocyte activity in canine visceral leishmaniosis. Vet. Parasitol. $51,49-59$. 
Martinez-Moreno, A., Moreno, T., Martinez-Moreno, F.J., Acosta, I., Hernandez, S., 1995. Humoral and cell-mediated immunity in natural and experimental canine leishmaniasis. Vet. Immunol. Immunopathol. $48,209-220$

Marzochi, M.C., Coutinho, S.G., De Souza, W.J., De Toledo, L.M., Grimaldi Jr., G., Momen, H., Pacheco, R., Da, S., Sabroza, P.C., De Souza, M.A., Rangel Jr., F.B., 1985. Canine visceral leishmaniasis in Rio de Janeiro, Brazil. Clinical, parasitological, therapeutical and epidemiological findings (1977-1983). Mem. Inst. Oswaldo Cruz 80, 349-357.

Mauricio, I.L., Stothard, J.R., Miles, M.A., 2000. The strange case of Leishmania chagasi. Parasitol. Today 16, 188-189.

Montenegro, J., 1926. Cutaneous reaction in leishmaniasis. Arch. Dermatol. Syph. 13, 187-194.

Nacy, C.A., Nelson, B.J., Meltzer, M.S., Green, S.J., 1991. Cytokines that regulate macrophage production of nitrogen oxides and expression of antileishmanial activities. Res. Immunol. 142, 573-576.

Nieto, C.G., García-Alonso, M., Requena, J.M., Mirón, C., Soto, M., Alonso, C., Navarrete, I., 1999. Analysis of the humoral immune response against total and recombinant antigens of Leishmania infantum: correlation with disease progression in canine experimental leishmaniasis. Vet. Immunol. Immunopathol. 67, 117-130.

Noli, C., Auxilia, S.T., 2005. Treatment of canine Old World visceral leishmaniasis: a systematic review. Vet. Dermatol. 16, 213-232.

Palatnik-de-Sousa, C.B., Santos, W.R., França-Silva, J.C., da Costa, R.T., Reis, A.B., Palatnik, M., Mayrink, W., Genaro, O., 2001. Impact of canine control on the epidemiology of canine and human visceral leishmaniasis in Brazil. Am. J. Trop. Med. Hyg. 65, 510-517.

Pinelli, E., Killick-Kendrick, R., Wagenaar, J., Bernadina, W., Del Real, G., Ruitenberg, J., 1994. Cellular and humoral immune responses in dogs experimentally and naturally infected with Leishmania infantum. Infect. Immun. 62, 229-235.

Pinelli, E., Gonzalo, R.M., Boog, C.J., Rutten, V.P., Gebhard, D., del Real, G., Ruitenberg, J., 1995. Leishmania infantum-specific T cell lines derived from asymptomatic dogs that lyse infected macrophages in a major histocompatibility complex-restricted manner. Eur. J. Immunol. 25, 1594-1600.

Pinelli, E., Rutten, V.P.M., Bruysters, M., Moore, P.F., Ruitemberg, J., 1999a. Compensation for decreased expression of B7 molecules on Leishmania infantum-infected canine macrophages results in restoration of parasite-specific T-cell proliferation and gamma interferon production. Infect. Immun. 67, 237-243.

Pinelli, E., Van Der Kaaij, S.Y., Slappendel, R., Fragio, C., Ruitenberg, E.J., Bernadina, W., Rutten, V.P., 1999b. Detection of canine cytokine gene expression by reverse transcription-polymerase chain reaction. Vet. Immunol. Immunopathol. 69, 121-126.

Quinnell, R.J., Courtenay, O., Garcez, L.M., Kaye, P.M., Shaw, M.A., Dye, C., Day, M.J., 2003. IgG subclass responses in a longitudinal study of canine visceral leishmaniasis. Vet. Immunol. Immunopathol. 91, 161168.

Reed, S.G., Badaró, R., Masur, H., Carvalho, E.M., Lorenco, R., Lisboa, A., Teixeira, R., Johnson Jr., W.D., Jones, T.C., 1986. Selection of a skin test antigen for American visceral leishmaniasis. Am. J. Trop. Med. Hyg. 35, 79-85.

Reis, A., 2001. Avaliação de parâmetros laboratoriais e imunológicos de cães naturalmente infectados com Leishmania (Leishmania) chagasi, portadores de diferentes formas clínicas da infecção. Thesis. UFMG. $176 \mathrm{pp}$.

Reis, A.B., Martins-Filho, O.A., Teixeira-Carvalho, A., Carvalho, M.G., Mayrink, W., Franca-Silva, J.C., Giunchetti, R.C., Genaro, O., Corrêa-Oliveira, R., 2006a. Parasite density and impaired biochemical/hematological status are associated with severe clinical aspects of canine visceral leishmaniasis. Res. Vet. Sci. 81, 68-75.

Reis, A.B., Teixeira-Carvalho, A., Vale, A.M., Marques, M.J., Giunchetti, R.C., Mayrink, W., Guerra, L.L., Andrade, R.A., Correa-Oliveira, R., MartinsFilho, O.A., 2006b. Isotype patterns of immunoglobulins: hallmarks for clinical status and tissue parasite density in Brazilian dogs naturally infected by Leishmania (Leishmania) chagasi. Vet. Immunol. Immunopathol. 112, 102-116.

Reis, A.B., Teixeira-Carvalho, A., Giunchetti, R.C., Guerra, L.L., Carvalho, M.G., Mayrink, W., Genaro, O., Corrêa-Oliveira, R., Martins-Filho, O.A., 2006c. Phenotypic features of circulating leucocytes as immunological markers for clinical status and bone marrow parasite density in dogs naturally infected by Leishmania chagasi. Clin. Exp. Immunol. 146, 303-311.
Reithinger, R., Davies, C.R., 1999. Is the domestic dog (Canis familiaris) a reservoir host of American cutaneous leishmaniasis? A critical review of the current evidence. Am. J. Trop. Med. Hyg. 61, 530-541.

Rogers, K.S., Barton, C.L., Landis, M., 1993. Canine and feline lymph nodes. Part II. Diagnosis, evaluation and lymphadenopathy. Compendium 15, 1493-1501.

Rodriguez-Cortes, A., Fernandez-Bellon, H., Ramis, A., Ferrer, L., Alberola, J., Solano-Gallego, L., 2007. Leishmania-specific isotype levels and their relationship with specific cell-mediated immunity parameters in canine leishmaniasis. Vet. Immunol. Immunopathol. 116, 190-198.

Sacks, D.L., Lal, S.L., Shrivastava, S.N., Blackwell, J., Neva, F.A., 1987. An analysis of T cell responsiveness in Indian kala-azar. J. Immunol. 138, 908-913.

Sanchez, M.A., Diaz, N.L., Zerpa, O., Negron, E., Convit, J., Tapia, F.J., 2004. Organ-specific immunity in canine visceral leishmaniasis: analysis of symptomatic and asymptomatic dogs naturally infected with Leishmania chagasi. Am. J. Trop. Med. Hyg. 70, 618-624.

Solano-Gallego, L., Llull, J., Ramos, G., Riera, C., Arboix, M., Alberola, J., Ferrer, L., 2000. The Ibizian hound presents a predominantly cellular immune response against natural Leishmania infection. Vet. Parasitol. $90,37-45$

Solano-Gallego, L., Riera, C., Roura, X., Iniesta, L., Gallego, M., Valladares, J.E., Fisa, R., Castillejo, S., Alberola, J., Ferrer, L., Arboix, M., Portus, M., 2001a. Leishmania infantum-specific IgG, IgG1 and IgG2 antibody responses in healthy and ill dogs from endemic areas. Evolution in the course of infection and after treatment. Vet. Parasitol. 96, 265276.

Solano-Gallego, L., Llull, J., Arboix, M., Ferrer, L., Alberola, J., 2001 b. Evaluation of the efficacy of two leishmanins in asymptomatic dogs. Vet. Parasitol. 102, 163-166.

Solano-Gallego, L., Fernández-Bellon, H., Morell, P., Fondevila, D., Alberola, J., Ramis, A., Ferrer, L., 2004. Histological and immunohistochemical study of clinically normal skin of Leishmania infantum-infected dogs. J. Comp. Pathol. 130, 7-12.

Solano-Gallego, L., Llull, J., Ramis, A., Fernández-Bellon, H., Rodríguez, A., Ferrer, L., Alberola, J., 2005. Longitudinal study of dogs living in an area of Spain highly endemic for leishmaniasis by serologic analysis and the leishmanin skin test. Am. J. Trop. Med. Hyg. 72, 815-818.

Stauber, L.A., 1955. Leishmaniasis in the hamster. In: Cole, W.H. (Ed.), Some Physiological Aspects and Consequence of Parasitism. Rugers University Press, New York.

Strauss-Ayali, D., Baneth, G., Jaffe, C.L., 2007. Splenic immune responses during canine visceral leishmaniasis. Vet. Res. 38, 547-564.

Tarantino, C., Rossi, G., Kramer, L.H., Perrucci, S., Cringoli, G., Macchioni, G., 2001. Leishmania infantum and Neospora caninum simultaneous skin infection in a young dog in Italy. Am. J. Trop. Med. Hyg. 102, 77-83.

Teixeira-Carvalho, A., Martins-Filho, A.O., Andrade, Z.A., Cunha-Mello, J.R., Wilson, R.A., Correa-Oliveira, R., 2002. The study of T-cell activation in peripheral blood and spleen of hepatosplenic patients suggests an exchange of cells between these two compartments in advanced human Schistosomiasis mansoni infection. Scand. J. Immunol. 56, 315-322.

Tryphomas, L., Zawdzka, Z., Bernard, M.A., Janzen, E.A., 1977. Visceral leishmaniasis in a dog: clinical hematological and pathological observations. Can. J. Comp. Med. 41, 1-12.

Tafuri, W.L., De Oliveira, M.R., Melo, M.N., Tafuri, W.L., 2001. Canine visceral leishmaniasis: a remarkable histopathological picture of one case report from Brazil. Vet. Parasitol. 3, 203-212.

Tafuri, Wg.L., Santos, R.L., Arantes, R.M.E., Gonçalves, R., Melo, M.N., Michalik, M.S.M., Tafuri, W.L., 2004. An alternative immunohistochemical method for detecting Leishmania amastigotes in paraffinembedded canine tissues. J. Immunol. Methods 292, 17-23.

Tesh, R.B., 1995. Control of zoonotic visceral leishmaniasis: is it time to change strategies? Am. J. Trop. Med. Hyg. 52, 287-292.

Torres, C.M., 1941. Alterações cutâneas do cão no kala-azar sul-americano. Mem. Inst. Oswaldo Cruz 36, 37-67.

Vercammen, F., Fernandez-Perez, F.J., del Amo, C., Alunda, J.M., 2002 Follow-up of Leishmania infantum naturally infected dogs treated with allopurinol: immunofluorescence antibody test, ELISA and Western blot. Acta Trop. 84, 175-181.

World Health Organization, 2000. Leishmania/HIV co-infection SouthWestern Europe 1990-1998: retrospective analysis of 965 cases. WHO/LEISH/2000, Geneva. Electronic access: http://whqlibdoc. who.int/hq/2000/WHO_LEISH_2000.42.pdf. 